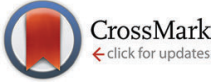

Cite this: Chem. Commun., 2015, 51,6018

Received 9th February 2015, Accepted 21st February 2015

DOI: $10.1039 / c 5 c c 01224 d$

www.rsc.org/chemcomm

\title{
A red-shifted photochromic sulfonylurea for the remote control of pancreatic beta cell function $\dagger$
}

\author{
J. Broichhagen, ${ }^{a}$ J. A. Frank, ${ }^{a}$ N. R. Johnston, ${ }^{b}$ R. K. Mitchell, ${ }^{b}$ K. Šmid, ${ }^{a}$ \\ P. Marchetti, ${ }^{c}$ M. Bugliani, ${ }^{c}$ G. A. Rutter, ${ }^{\text {b }}$ D. Trauner ${ }^{\star a}$ and D. J. Hodson ${ }^{b}$
}

\begin{abstract}
Azobenzene photoresponsive elements can be installed on sulfonylureas, yielding optical control over pancreatic beta cell function and insulin release. An obstacle to such photopharmacological approaches remains the use of ultraviolet-blue illumination. Herein, we synthesize and test a novel yellow light-activated sulfonylurea based on a heterocyclic azobenzene bearing a push-pull system.
\end{abstract}

Type 2 diabetes (T2D) is a modern pandemic currently affecting $\sim 6 \%$ of the global population. This disease is characterized by diminished insulin secretion from pancreatic beta cells, which together with peripheral resistance to the secreted hormone, leads to defective glucose homeostasis. ${ }^{1}$ The resulting elevated glucose concentration drives a variety of complications including heart disease, cancer, retinal degeneration, and nerve and vascular problems. $^{2}$

While current medical treatments work well, they are associated with complications largely due to off-target or persistent actions. ${ }^{3}$ Moreover, they are unable to recreate pulsatile insulin release, a more effective signal for glucoregulation. ${ }^{4}$ Thus, T2D is ideally suited to photopharmacology, which harnesses the precision of light to spatiotemporally deliver drug activity. ${ }^{5}$ We have recently shown that a sulfonylurea possessing an azobenzene photoresponsive element (a.k.a. AzoSulfonylurea) can be used to optically control beta cell function and insulin release via its effects on ATP-sensitive potassium $\left(\mathrm{K}_{\mathrm{ATP}}\right)$ channels and Exchange Protein directly Activated by cAMP 2 A (Epac2A) signaling. ${ }^{6}$

However, a significant barrier to the use of such 'azo-drugs' for T2D treatment is their ultraviolet-blue absorption spectra, increasing phototoxicity and limiting tissue penetration due to photon scattering. ${ }^{7}$ By contrast, visible/near infrared wavelengths demonstrate better penetrance in the body. ${ }^{8}$

\footnotetext{
${ }^{a}$ Department of Chemistry and Center for Integrated Protein Science, LMU Munich, Munich, Germany. E-mail: dirk.trauner@lmu.de

${ }^{b}$ Section of Cell Biology and Functional Genomics, Department of Medicine, Imperial College London, LondonW12 ONN, UK. E-mail: d.hodson@imperial.ac.uk ${ }^{c}$ Department of Clinical and Experimental Medicine, Islet Cell Laboratory, University of Pisa, Pisa, Italy

$\dagger$ Electronic supplementary information (ESI) available. See DOI: 10.1039/c5cc01224d
}

Spurred on by recent studies of ortho- or para-substituted azobenzenes, ${ }^{9-11}$ we therefore devised a novel approach for the synthesis of wavelength-tuned photopharmaceuticals with red-shifted photochromism. An AzoSulfonylurea based on glimepiride was achieved by installing a heterocyclic aromatic unit, rather than sterically bulky electron-donating halogen or amine moieties (Scheme 1).

Starting with the deacetylation of acetazolamide (1) in refluxing $\mathrm{HCl}$, heterocycle 2 was obtained that could be further diazotized with in situ generated $\mathrm{HNO}_{2}$. Trapping the resulting diazonium salt with $N, N$-diethylaniline generated sulfonamide azobenzene 3. Finally, reaction with cyclohexyl isocyanate yielded JB558 via acylation of the sulfonamide, giving unprecedented access to a sulfonylurea containing a heterocyclic azobenzene. While yields were reduced compared to the previously described JB253 (37\% versus 97\%), ${ }^{6}$ this was most likely due to the

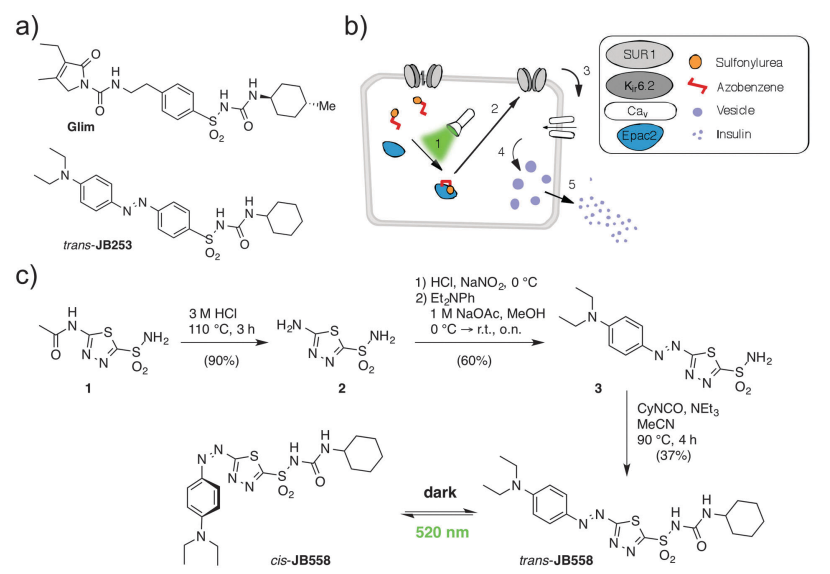

Scheme 1 (a) Structures of glimepiride (Glim) and the original blue lightresponsive AzoSulfonylurea JB253 for comparison. (b) The logic of a red-shifted AzoSulfonylurea. Following illumination with green-yellow light (1), the AzoSulfonylurea binds Epac2A, closing $\mathrm{K}_{\text {ATP }}$ channels (2) and opening voltagedependent $\mathrm{Ca}^{2+}$ channels $\left(\mathrm{Ca}_{\mathrm{v}}\right)$ (3). This allows optical control of $\mathrm{Ca}^{2+}$ influx (4) and insulin secretion (5). (c) Synthesis of the AzoSulfonylurea JB558 that can be switched from the trans- to the cis-isomer using green/yellow light. 
presence of a less reactive sulfonamide intermediate, as predicted by the lower $\mathrm{p} K_{\mathrm{a}}$ value for 3 (7.36, Fig. S1, ESI $\dagger$ ) and JB558 (2.35, see ESI $\dagger$ ).

JB558 possessed a red-shifted absorption spectrum $\left(\lambda_{\max }=\right.$ $526 \mathrm{~nm}$ ) in DMSO (Fig. 1a), and could be repeatedly photoconverted to its cis-state with green-yellow light $(\lambda=520 \mathrm{~nm})$ (Fig. 1b). Thermal back relaxation occurred rapidly in the dark and switching kinetics were within the millisecond range $\left(\tau_{c i s}=64.9 \pm 1.5 \mathrm{~ms}\right.$; $\tau_{\text {trans }}=410.8 \pm 12.6 \mathrm{~ms}$ ), without obvious decomposition (Fig. 1b). JB558 was stable in the presence of Escherichia coli azoreductase, an enzyme expected to limit oral bioavailability through diazene cleavage in the intestine (Fig. S2, ESI $\dagger$ ).

To determine the binding affinity of JB558 to the $\mathrm{K}_{\mathrm{ATP}}$ channel subunit SUR1, as well as Epac2A, [3H]-glibenclamide displacement and FRET assays were performed. While trans-JB558 bound SUR1 with $\sim 10000$-fold less affinity than glimepiride ( $\mathrm{IC}_{50}$ (trans-JB558) $\left.=37.3 \mu \mathrm{M} ; \mathrm{IC}_{50}(\mathrm{Glim})=1.8 \mathrm{nM}\right)$ (Fig. 2a), it was able to strongly and light-dependently activate an Epac2-camps biosensor containing the sulfonylurea binding domain (Fig. $2 \mathrm{~b}-\mathrm{d}$ ). ${ }^{12}$

Electrophysiological recordings of $\mathrm{K}^{+}$currents in HEK293TSUR1-Kir6.2 cells revealed partial $\mathrm{K}_{\mathrm{ATP}}$ channel blockade by
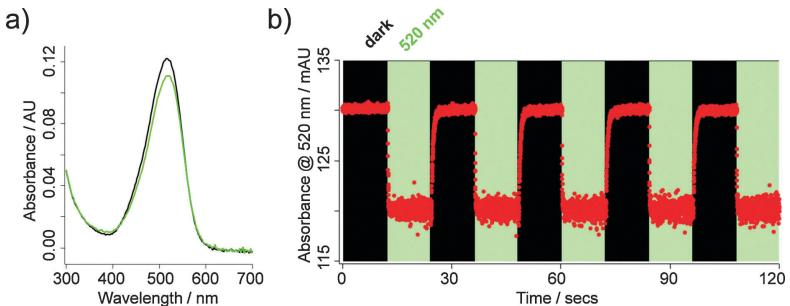

Fig. 1 (a) UV-Vis spectra of JB558 in DMSO following illumination with $\lambda=520 \mathrm{~nm}$ (green) or under dark-adapted conditions (black). (b) Robust photoswitching between cis- and trans-JB558 induced with $\lambda=520 \mathrm{~nm}$ and dark, respectively.
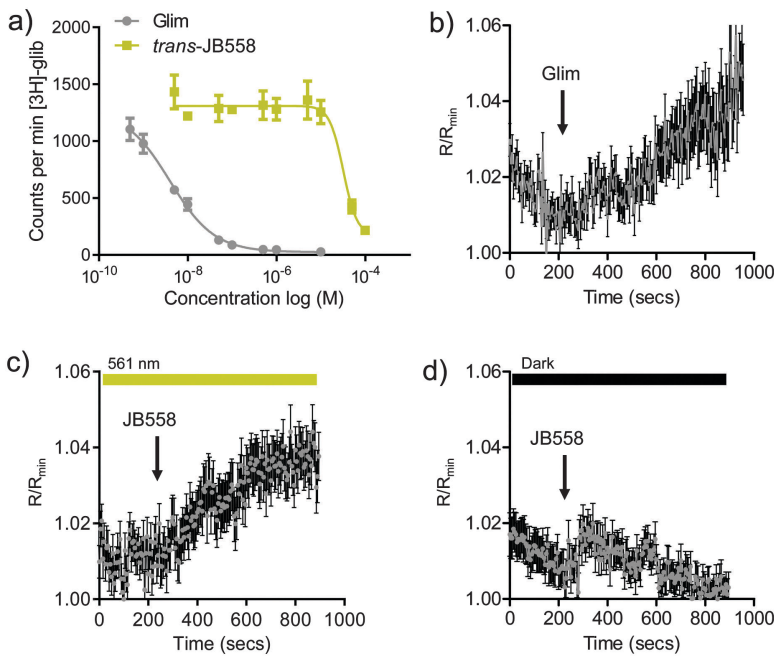

Fig. 2 (a) trans-JB558 and glimepiride (Glim) displace [3H]-glibenclamide from SUR1 ( $n=3$ repeats). (b) Glimepiride decreases FRET (shown here as an increase in $R / R_{\min }$ ) in HEK293T cells expressing full length Epac2-camps ( $n=32$ cells). (c) As for (b) but cis-JB558 ( $\lambda=561 \mathrm{~nm})(n=41$ cells). (d) As for (c) but trans-JB558 (dark) ( $n=37$ cells). Values represent mean \pm s.e.m.
trans-JB558, presumably due to the momentary stationary state favoring some continued cis-isomerization (Fig. S3, ESI $\dagger$ ).

We next assessed the photoswitching properties of JB558 in native beta cells where sulfonylurea-mediated $\mathrm{K}_{\mathrm{ATP}}$ channelEpac2A signaling is intimately linked to voltage-dependent $\mathrm{Ca}^{2+}$ channel (VDCC) activity and insulin exocytosis. ${ }^{13-16}$ As expected, JB558 was able to evoke large increases in intracellular $\mathrm{Ca}^{2+}$ concentrations in $\sim 60 \%$ of beta cells following exposure to yellow $(\lambda=561 \pm 5 \mathrm{~nm})$ (Fig. 3a and b), but not violet $(\lambda=405 \pm 5 \mathrm{~nm})$ light (Fig. 3c). These effects were potentiated using a high concentration of glimepiride (Fig. 3d), and abrogated using diazoxide (Fig. 3e) to force open the $\mathrm{K}_{\mathrm{ATP}}$ channel pore. Repeated switching of cytosolic $\mathrm{Ca}^{2+}$ concentrations could be achieved in the same islet following a brief period of dark exposure to induce trans-JB558 accumulation (Fig. 3f).

a)
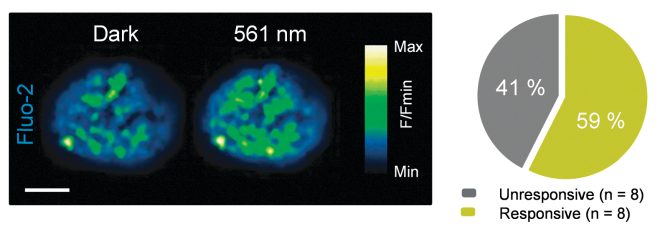

b)
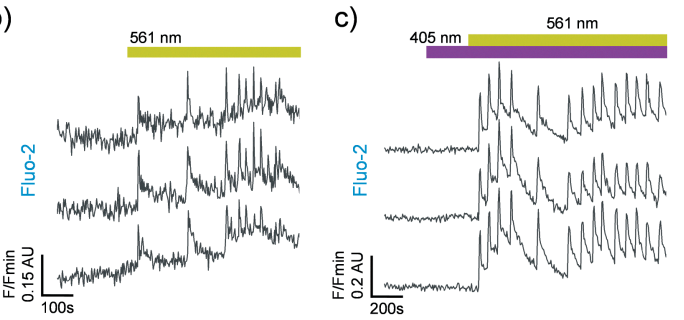

d)
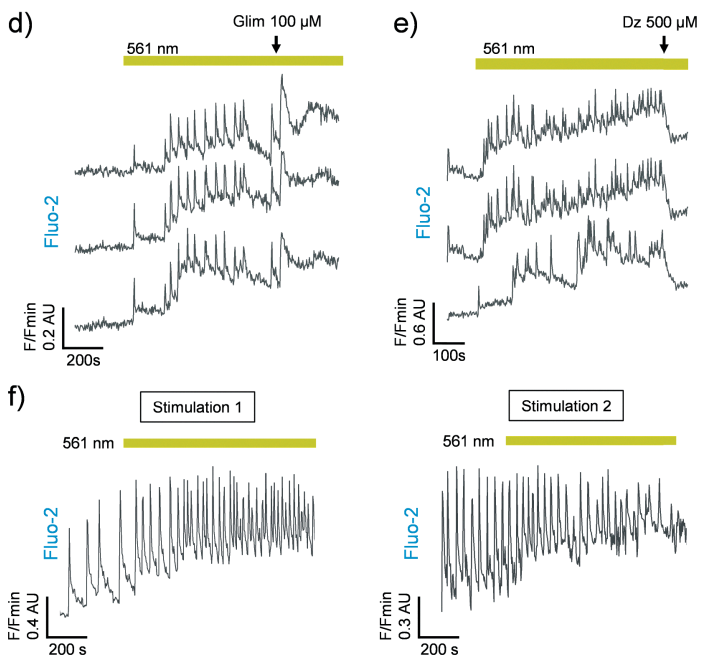

Fig. 3 (a) JB558 increases intracellular $\mathrm{Ca}^{2+}$ concentrations in $59 \%$ of beta cells residing within rodent islets of Langerhans following illumination with $\lambda=561 \mathrm{~nm}$ (scale bar $=75 \mu \mathrm{m})$ ( $n=8$ islets). (b) Photoswitching is rapid following exposure to $\lambda=561 \mathrm{~nm}$. (c) As for (b), but showing the absence of photoswitching with $\lambda=405 \mathrm{~nm}$. (d) A high concentration of glimepiride (Glim) augments JB558-stimulated $\mathrm{Ca}^{2+}$ rises. (e) Diazoxide (Dz) reverses cis-JB558-induced $\mathrm{Ca}^{2+}$ fluxes. (f) Reversible manipulation of $\mathrm{Ca}^{2+}$ transients can be achieved in the same islet following thermal back relaxation of JB558 in the dark (5 min between stimulation 1 and 2). Traces represent $n=6-10$ recordings from 3 animals. Islets were maintained in $5 \mathrm{mM}$ D-glucose throughout. 
Similar to the results observed in rodent tissue, cis-JB588 was able to confer light-sensitivity on $\mathrm{Ca}^{2+}$-spiking activity in human pancreatic islets (Fig. 4a-c), and this effect could be reversed following 5 min relaxation in the dark (Fig. 4d).

To link photocontrol of $\mathrm{Ca}^{2+}$ levels with insulin secretion, batches of rodent islets were incubated with JB558 and exposed to either dark (no illumination) or light $(\lambda=560 \pm 10 \mathrm{~nm})$. JB558-treated islets kept under dark conditions were no different to controls $(5 \mathrm{mM}$ glucose-alone) (Fig. 5a), suggesting that the observed stationary state $\mathrm{K}_{\mathrm{ATP}}$ channel block was insufficient to elicit exocytosis. By contrast, irradiation dramatically stimulated insulin release (Fig. 5a). Finally, cytotoxicity assays demonstrated that JB558 did not adversely affect cell viability, as assessed using the vital stain calcein and the necrosis indicator propidium iodide (Fig. $5 \mathrm{~b}$ and c).

The data presented here outline a synthetic route for the production of AzoSulfonylureas with red-shifted photochromism. Consistent with its sulfonylurea backbone, JB558 was able to bind SUR1 and activate Epac2A. Formation of cis-JB558 occurred with green-yellow light $(\lambda=520-561 \mathrm{~nm})$, and thermal back relaxation in the dark yielded trans-JB558. While photoconversion between cis- and trans-forms was rapid in solution, it was slower in the tissue setting, taking minutes for reisomerization. An effect of Fluo-2 excitation on the isomer equilibrium cannot be excluded, although illumination at $\lambda=491 \mathrm{~nm}$ per se was unable to evoke $\mathrm{Ca}^{2+}$ rises in either Fluo-2- or Fura2 $(\lambda=340 \mathrm{~nm} / 380 \mathrm{~nm})$-loaded islets (Fig. S4, ESI $\dagger$ ).

a)

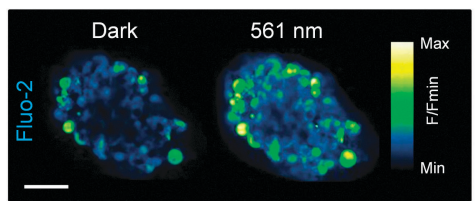

b)

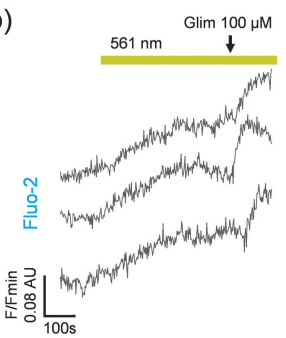

c)

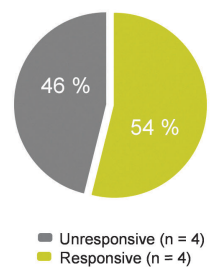

d)
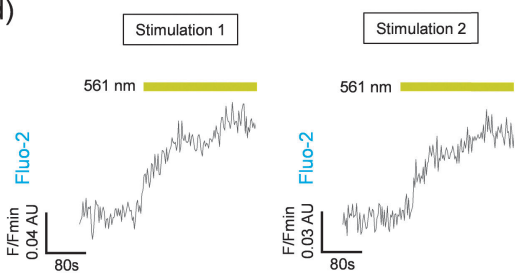

Fig. 4 (a) JB558 increases intracellular $\mathrm{Ca}^{2+}$ concentrations in human beta cells in response to illumination with $561 \mathrm{~nm}$ to induce cis-formation (scale bar $=50 \mu \mathrm{m}$ ). (b) Photoswitching is rapid following exposure to $561 \mathrm{~nm}$ and can be potentiated with glimepiride (Glim). (c) cis-JB588 activates $54 \%$ of beta cells ( $n=4$ islets). (d) Reversible manipulation of $\mathrm{Ca}^{2+}$ rises following thermal back relaxation of JB558 in the dark ( 5 min between stimulation 1 and 2). Traces represent $n=3-9$ recordings from a single donor. Islets were maintained in $5 \mathrm{mM}$ D-glucose throughout. a)

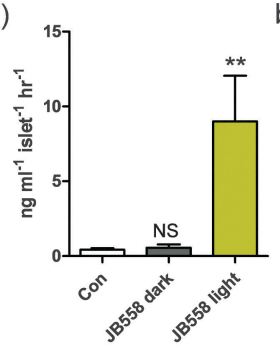

b)

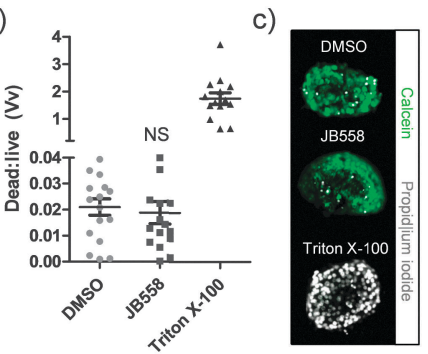

Fig. 5 (a) JB558-treated islets respond to illumination with $\lambda=560 \mathrm{~nm}$ by increasing insulin secretion ( ${ }^{\star *} P<0.01$ and NS, non-significant versus Con; one-way ANOVA). (b) Incubation with JB558 for $1 \mathrm{~h}$ did not adversely affect cell viability versus dimethyl sulfoxide (DMSO), as assessed by the ratio of propidium iodide (dead) : calcein (live) fluorescence (positive control; Triton X-100) (NS, non-significant versus Con; one-way ANOVA). (c) Representative images of islets stained with calcein and propidium iodide. In all cases, $n=36$ islets per treatment group from 6 animals. Values represent mean \pm s.e.m.

A more plausible explanation is the inactivation of beta cell Epac2A-signaling, which may lag behind that of JB558 due to persistent mobilization of intracellular $\mathrm{Ca}^{2+} \cdot 1,17$ Such tissue effects may be desirable for the development of photopharmaceuticals, since pulsed illumination would reduce phototoxicity, while sustaining compound activity to match long-lasting (dozens of minutes) insulin peaks. ${ }^{4}$ Indeed, JB558 displayed almost 3-fold more potency than its blue-light activated predecessor JB253, ${ }^{6}$ most likely due to slower back-relaxation during the light pulses used in the secretion assays.

Neither were we able to detect photoswitching of $\mathrm{K}^{+}$currents in HEK293T cells overexpressing $K_{\text {ATP }}$ channels, free from orthogonal wavelengths (Fig. S5, ESI $\dagger$ ). This was likely because HEK293T cells do not express sufficient Epac2A to allow JB558 to properly toggle $\mathrm{K}_{\mathrm{ATP}}$ activity, ${ }^{13,15,18}$ and/or the inability to deliver sufficient illumination using the non-coherent source on our patch-clamp setup $\left(\varepsilon_{520 \mathrm{~nm}}(\right.$ JB558 $)=1.14 \times 10^{5} \mathrm{~mol}^{-1} \mathrm{~cm}^{-1}$; see ESI $\left.\dagger\right)$.

Nonetheless, we clearly show that JB558 light-dependently binds Epac2A, allowing optical control of cell function and insulin secretion with $\lambda=560 \mathrm{~nm}$ in the most physiologically-relevant testbed, viz. the islets of Langerhans. Thus, JB558 represents a blueprint for red-shifted AzoSulfonylureas based upon heterocyclic azobenzenes. Further studies are now warranted to improve isomerization kinetics in tissue to improve the use of JB558 as a research tool for rapid $\mathrm{K}_{\mathrm{ATP}}$ channel manipulation. Importantly, similar synthetic approaches may also be applicable to other clinically-relevant azobenzene-possessing compounds where steric hindrance may affect molecule motion e.g. neuromodulators, ${ }^{19}$ neurotransmitters, ${ }^{20,21}$ enzymes $^{22}$ and antibiotics. ${ }^{23}$

J.B. was supported by a European Foundation for the Study of Diabetes (EFSD) Albert Renold Young Scientist Fellowship and a Studienstiftung des deutschen Volkes PhD studentship. N.R.J. was supported by a Diabetes UK RW and JM Collins Studentship (12/0004601). J.A.F. was supported by a Collaborative Research Centre Grant (SFB1032). G.A.R. was supported by Wellcome Trust Senior Investigator (WT098424AIA), MRC Programme (MR/J0003042/1), Diabetes UK Project Grant (11/0004210) and Royal Society Wolfson Research Merit Awards. D.T. was supported by an 
Advanced Grant from the European Research Commission (268795). D.J.H. was supported by a Diabetes UK R.D. Lawrence Research Fellowship (12/0004431). The work leading to this publication has received support from the Innovative Medicines Initiative Joint Undertaking under grant agreement no. 155005 (IMIDIA), resources of which are composed of a financial contribution from the European Union's Seventh Framework Programme (FP7/2007-2013) and EFPIA companies' in kind contribution (G.A.R.).

\section{Notes and references}

1 G. A. Rutter, Mol. Aspects Med., 2001, 22, 247-284.

2 J. M. Forbes and M. E. Cooper, Physiol. Rev., 2013, 93, 137-188.

3 S. Bolen, L. Feldman, J. Vassy, L. Wilson, H. C. Yeh, S. Marinopoulos, C. Wiley, E. Selvin, R. Wilson, E. B. Bass and F. L. Brancati, Ann. Intern. Med., 2007, 147, 386-399.

4 S. Seino, T. Shibasaki and K. Minami, J. Clin. Invest., 2011, 121, 2118-2125.

5 W. A. Velema, W. Szymanski and B. L. Feringa, J. Am. Chem. Soc., 2014, 136, 2178-2191.

6 J. Broichhagen, M. Schönberger, S. C. Cork, J. A. Frank, P. Marchetti, M. Bugliani, A. M. J. Shapiro, S. Trapp, G. A. Rutter, D. J. Hodson and D. Trauner, Nat. Commun., 2014, 5, 5116.

7 J. V. Frangioni, Curr. Opin. Chem. Biol., 2003, 7, 626-634.

8 A. Bakker, B. Smith, P. Ainslie and K. Smith, Applied Aspects of Ultrasonography in Humans, InTech, Near-Infrared Spectroscopy, 2012.

9 M. A. Kienzler, A. Reiner, E. Trautman, S. Yoo, D. Trauner and E. Y. Isacoff, J. Am. Chem. Soc., 2013, 135, 17683-17686.
10 A. Rullo, A. Reiner, A. Reiter, D. Trauner, E. Y. Isacoff and G. A. Woolley, Chem. Commun., 2014, 50, 14613-14615.

11 A. A. Beharry, O. Sadovski and G. A. Woolley, J. Am. Chem. Soc., 2011, 133, 19684-19687.

12 K. J. Herbst, C. Coltharp, L. M. Amzel and J. Zhang, Chem. Biol., 2011, 18, 243-251.

13 C. L. Zhang, M. Katoh, T. Shibasaki, K. Minami, Y. Sunaga, H. Takahashi, N. Yokoi, M. Iwasaki, T. Miki and S. Seino, Science, 2009, 325, 607-610.

14 G. A. Rutter and D. J. Hodson, Cell. Mol. Life Sci., 2014, 72, 453-467.

15 M. Almahariq, F. C. Mei and X. Cheng, Trends Endocrinol. Metab., 2014, 25, 60-71.

16 L. Aguilar-Bryan, J. P. t. Clement, G. Gonzalez, K. Kunjilwar, A. Babenko and J. Bryan, Physiol. Rev., 1998, 78, 227-245.

17 C. A. Leech, O. G. Chepurny and G. G. Holz, Vitam. Horm., 2010, 84, 279-302.

18 T. Tsalkova, F. C. Mei, S. Li, O. G. Chepurny, C. A. Leech, T. Liu, G. G. Holz, V. L. Woods, Jr. and X. Cheng, Proc. Natl. Acad. Sci. U. S. A., 2012, 109, 18613-18618.

19 M. Stein, S. J. Middendorp, V. Carta, E. Pejo, D. E. Raines, S. A. Forman, E. Sigel and D. Trauner, Angew. Chem., Int. Ed. Engl., 2012, 51, 10500-10504.

20 M. Volgraf, P. Gorostiza, R. Numano, R. H. Kramer, E. Y. Isacoff and D. Trauner, Nat. Chem. Biol., 2006, 2, 47-52.

21 I. Tochitsky, M. R. Banghart, A. Mourot, J. Z. Yao, B. Gaub, R. H. Kramer and D. Trauner, Nat. Chem., 2012, 4, 105-111.

22 J. Broichhagen, I. Jurastow, K. Iwan, W. Kummer and D. Trauner, Angew. Chem., Int. Ed. Engl., 2014, 53, 7657-7660.

23 W. A. Velema, J. P. van der Berg, M. J. Hansen, W. Szymanski, A. J. Driessen and B. L. Feringa, Nat. Chem., 2013, 5, 924-928. 